\title{
Efficacy and safety of low-dose everolimus combined with endocrine drugs for patients with hormone receptor-positive, human epidermal growth factor receptor 2-negative metastatic breast cancer
}

\author{
Hui-Qiang Zhang", Jin-Mei Zhou", Shao-Hua Zhang, Li Bian, Jin-Yi Xiao, Xiao-Peng Hao, Ze-Fei Jiang, \\ Tao Wang^
}

Department of Breast Oncology, The Fifth Medical Center of Chinese PLA General Hospital, Beijing, China

Contributions: (I) Conception and design: T Wang, ZF Jiang; (II) Administrative support: T Wang, ZF Jiang; (III) Provision of study materials or patients: All authors; (IV) Collection and assembly of data: HQ Zhang, JM Zhou; (V) Data analysis and interpretation: T Wang, ZF Jiang, HQ Zhang, JM Zhou; (VI) Manuscript writing: All authors; (VII) Final approval of manuscript: All authors.

\#These authors contributed equally to this work.

Correspondence to: Tao Wang; Ze-Fei Jiang. Department of Breast Oncology, The Fifth Medical Center of Chinese PLA General Hospital, Beijing, China. Email: wangtao733073@163.com; jiangzefei@csco.org.cn.

\begin{abstract}
Background: To analyze the efficacy and safety of everolimus $5 \mathrm{mg} /$ day in combination with endocrine drugs in the treatment of hormone receptor-positive, human epidermal growth factor receptor 2 (HER2)negative metastatic breast cancer using real-world clinical data.

Methods: Clinical data of hormone receptor (HR)-positive and HER2-negative patients with advanced breast cancer treated with everolimus combined with endocrine drugs in our center between August 2012 and May 2017 were retrospectively analyzed. Curative effect and adverse reactions were evaluated.

Results: A total of 110 patients were enrolled in this study, and $87.3 \%$ received salvage chemotherapy. The median number of salvage treatment lines was 5 (range: 1-19). The median follow-up duration was 12 months (range: 1-56.3 months), the overall response rate (ORR) was 6.4\%, the clinical benefit rate (CBR) was $31.8 \%$, the median progression-free survival (mPFS) was 4.0 months (95\% CI: 2.9-5.1 months), and the median overall survival (OS) was 17 months (95\% CI: 12.1-21.9 months). The mPFS for patients who received $\leq 2$ treatment line was 11.8 months (95\% CI: 4.3-19.3 months). Univariate and multivariate analyses suggested that absence of liver metastases, secondary endocrine resistance, and number of metastasis sites $<3$ were the main factors influencing the benefit of everolimus combined with endocrine therapy. The most common adverse events of grade 3 were: stomatitis (5.5\%), non-infectious pneumonia (1.8\%), and erythra (1.8\%). No grade 4 adverse reactions were observed.

Conclusions: Our results showed that everolimus ( $5 \mathrm{mg} /$ day) combined with endocrine therapy was effective and relatively safe for patients with hormone receptor-positive, HER2-negative metastatic breast cancer.
\end{abstract}

Keywords: Everolimus; hormone receptor-positive; metastatic breast cancer; endocrine therapy; real world

Submitted Jun 29, 2021. Accepted for publication Sep 18, 2021.

doi: $10.21037 /$ atm-21-4273

View this article at: https://dx.doi.org/10.21037/atm-21-4273

^ ORCID: 0000-0002-2823-7937. 


\section{Introduction}

Breast cancer is the most common malignant tumor in women, with an increasing incidence worldwide (1). Approximately 70-80\% of patients with breast cancer are diagnosed with hormone receptor (HR)-positive luminal A or luminal B subtype. Endocrine therapy is an important treatment approach for hormone receptor-positive patients; yet, some patients may develop primary and secondary resistance (2-4). Endocrine resistance seems to be associated with the activation of multiple growth factor signaling pathways. The interaction between estrogen receptors (ER) and the phosphatidylinositol 3-kinase/ protein kinase $\mathrm{B} / \mathrm{mammalians}$ target of rapamycin $(\mathrm{PI} 3 \mathrm{~K} /$ AKT/mTOR) signaling pathways can activate the ER pathway in a ligand-dependent and ligand-independent manner, which leads to further proliferation and development of tumors $(5,6)$. Recent preclinical studies have revealed that $\mathrm{PI} 3 \mathrm{~K} / \mathrm{AKT} / \mathrm{mTOR}$ pathway inhibitors may reverse endocrine resistance $(7,8)$.

Everolimus is an oral mTOR pathway inhibitor. Three prospective randomized studies, PrECOG0102 II, TAMRAD/GINECO, and BOLERO-2, along with the recent observational studies (STEPAUT, EVEREXES, 4EVER, and BRAWO), have demonstrated that everolimus combined with endocrine therapy can extend progressionfree survival in patients who did not respond well to initial endocrine therapy (9-12). The initial dose of everolimus used in overseas clinical studies was $10 \mathrm{mg} /$ day (13-15); however, in the BOLERO-2 and BALLET studies, the dose was reduced or the medication was discontinued due to the occurrence of adverse reactions in $62 \%$ and $59.6 \%$ of patients, respectively $(16,17)$. Ciccarese et al. (18) retrospectively analyzed the efficacy and safety of everolimus administered at different initial doses $(10 \mathrm{mg} /$ day, $5 \mathrm{mg} /$ day $)$ in 163 patients and reported no significant differences in the effectiveness and progression-free survival (PFS) between the two groups, while the tolerance was worse in the highdose group. Everolimus combined with endocrine therapy is likely safe and effective in older patients with HR-positive and HER2-negative metastatic breast cancer (19). There is no definite biomarker to predict the efficacy and safety of everolimus combined with endocrine drugs.

In China, there is still a lack of clinical data on everolimus. Gong et al. (20) showed that among the 54 patients who received an initial dose of everolimus of $10 \mathrm{mg} / \mathrm{day}$, the dose was reduced to $5 \mathrm{mg} / \mathrm{day}$ in 11 cases $(20 \%)$ due to adverse reactions. When we started administering everolimus, the initial dose of everolimus, which was $10 \mathrm{mg} /$ day, was not well tolerated by a high number of patients, and thus it was reduced to $5 \mathrm{mg} /$ day. In this study, we summarized real-world clinical data from our center to evaluate the effectiveness and safety of everolimus ( $5 \mathrm{mg} /$ day) combined with endocrine therapy in the treatment of hormone receptor-positive, human epidermal growth factor receptor 2 (HER2)-negative metastatic breast cancer. We present the following article in accordance with the STROBE reporting checklist (available at https://dx.doi. org/10.21037/atm-21-4273).

\section{Methods}

\section{Study population}

Clinical data of HR-positive and HER-2 negative patients with metastatic breast cancer who received everolimus combined with endocrine therapy in our center between August 2012 and May 2017 were selected. Inclusion criteria were: (I) aged $\geq 18$ years; (II) patients histopathologically confirmed with unresectable advanced or metastatic disease breast cancer; (III) HR-positive was defined as the proportion of positive cells $>1 \%$ using estrogen receptor (ER) or progestogen receptor (PR) immunohistochemistry (IHC), while HER2-negative was defined as IHC $0-1+$ or fluorescence in situ hybridization (FISH)/chromogenic in situ hybridization (CISH)-negative; (IV) Eastern Cooperative Oncology Group (ECOG) score was 0-2 points; $(\mathrm{V})$ patients who did not respond well to previous adjuvant endocrine therapy or salvage endocrine therapy, i.e., recurrence occurred during or after adjuvant endocrine therapy or progression during salvage endocrine therapy; (VI) according to the Response Evaluation Criteria in Solid Tumors (RECIST) version 1.1 standard, there was at least one extracranial measurable lesion or the patient had osteolytic or mixed bone metastases; (VII) normal blood routine tests and normal liver and kidney function. Exclusion criteria were: (I) pregnant or lactating; (II) life expectancy $<3$ months; (III) patients with uncontrolled lung diseases, severe infections, heart disease, and diabetes that required treatment, and coagulopathy to which the patients were intolerant; (IV) patients who previously suffered from other malignancies except for cervical cancer and non-melanoma skin cancer with a disease-free survival up to 5 years.

Complete medical data were collected, which included clear clinicopathological information, treatment records, 
evaluation of follow-up records, etc. All procedures performed in this study involving human participants were in accordance with the Declaration of Helsinki (as revised in 2013). The study was approved by ethics board of The Fifth Medical Center of the Chinese People's Liberation Army General Hospital (formerly named the 307 Hospital of Chinese People's Liberation Army) (No. 2010-06-64) and informed consent was taken from all the patients.

\section{Therapeutic methods}

The initial dose of everolimus was $5 \mathrm{mg} /$ day. If there were adverse reactions, the medication was adjusted to be permanently withdrawn or administration was delayed. Adverse events were treated according to guidelines. The endocrine drugs combined with everolimus were given based on previous clinical studies and at the discretion of the treating physicians. After excluding the endocrine drugs that have previously proven as ineffective, those administered during the present study included: selective estrogen receptor modulators (SERMs), including tamoxifen $(20 \mathrm{mg} / \mathrm{day}$, orally) and toremifin $(60 \mathrm{mg} / \mathrm{day}$, orally); aromatase inhibitors (AIs), including letrozole $(2.5 \mathrm{mg} /$ day, orally), anastrozole ( $1 \mathrm{mg} /$ day, orally), exemestane (25 mg/day, orally), fulvestrant (500 mg 1/28 day, intramuscular injection), and medroxyprogesterone $(1,000 \mathrm{mg} /$ day, orally).

\section{Efficacy evaluation criteria and observation indexes}

Drug efficacy and adverse events were routinely recorded every 2 months. The discontinuation of medication was based on the disease's progression or the emergence of intolerable adverse reactions. Follow up lasted until November 2017. Drug effectiveness was evaluated based on the RECIST version 1.1 criteria (21). Adverse reactions were judged according to the National Cancer Institute Common Terminology Criteria for Adverse Events version 4.0 (NCI-CTCAE 4.0). The observation indexes included PFS, overall survival (OS), clinical benefit rate (CBR), and objective response rate (ORR). Progression-free survival was defined as the time interval from the start of treatment to the first disease progression or death from any cause; $\mathrm{CBR}$ as the proportion of patients achieving a complete response (CR), partial response (PR), or stable disease (SD) for $\geq 6$ months during the treatment period. Overall response rate (ORR) referred to the proportion of patients with $\mathrm{CR}$ and $\mathrm{PR}$.

\section{Statistical analysis}

Statistical analyses were performed using SPSS 19.0 software. Measurement data were expressed as medians (ranges); count data were expressed as adoption rates or composition ratios. Chi-square test or Fisher's exact test was used to analyze group differences. Kaplan-Meier curves and log-rank tests were used for analyzing PFS and OS. Cox regression models were used to calculate the hazard ratios (HR) and 95\% confidence intervals (CIs). Log-rank tests were used for univariate analyses, including age, disease-free survival (DFS), number of metastatic organs (1-2 vs. $\geq 3$ ), visceral metastases, liver/lung/bone metastases, previous salvage chemotherapy, number of lines of endocrine therapy, endocrine resistance (primary vs. secondary), and combined drugs for endocrine therapy. Primary endocrine resistance was defined as relapse within 2 years of auxiliary endocrine therapy or progression within 6 months of salvage endocrine therapy. Secondary endocrine resistance was defined as relapse after 2 years of auxiliary endocrine therapy or within 1 year after the end of auxiliary endocrine therapy or progression after 6 months of salvage endocrine therapy. Cox multivariate analyses were performed based on the results of univariate analyses. $\mathrm{P}$ values and CIs were both bilaterally tested. $\mathrm{P}$ value $<0.05$ was considered as indicating statistical significance.

\section{Results}

\section{Patient characteristics and prior treatment}

A total of 110 patients were enrolled in this study. General patient data are shown in Table 1 . The median age was 50 years (range: $30-74$ years), and $63.6 \%$ of patients were postmenopausal. Premenopausal patients received druginduced ovarian function suppression and were treated in accordance with the criteria for postmenopausal patients. All patients had received endocrine therapy in the adjuvant or late stage, and $87.3 \%$ received salvage chemotherapy. Moreover, $69.1 \%$ of patients had visceral metastases, $72.7 \%$ had received $\geq 3$ treatment lines previously, and only $2.7 \%$ received everolimus as first line treatment. The median number of salvage treatment lines, median number of salvage endocrine therapy lines, and median number of salvage chemotherapy lines were 5 [1-19], 3 [1-8], and 3 [0-11], respectively. Moreover, $56.1 \%$ of patients had received chemotherapy, and $43.9 \%$ of patients had received endocrine therapy recently. 
Table 1 General characteristics

\begin{tabular}{|c|c|}
\hline Characteristic & Number of cases $(\%)$ \\
\hline \multicolumn{2}{|l|}{ Age (year) } \\
\hline Median [range] & $50[30-74]$ \\
\hline \multicolumn{2}{|l|}{ Body mass index $\left(\mathrm{kg} / \mathrm{m}^{2}\right)$} \\
\hline Median [range] & $24.1[17.8-34.8]$ \\
\hline Mean (SD) & $24.3(3.2)$ \\
\hline \multicolumn{2}{|l|}{ Menopausal status } \\
\hline Postmenopausal & $70(63.6)$ \\
\hline Premenopausal & $40(36.4)$ \\
\hline \multicolumn{2}{|l|}{ Disease-free survival (month) } \\
\hline Median [range] & $36[0-276]$ \\
\hline$\leq 12$ & $22(20.0)$ \\
\hline $12-24$ & $21(19.1)$ \\
\hline$>24$ & $67(60.9)$ \\
\hline \multicolumn{2}{|l|}{ Number of metastatic sites } \\
\hline 1 & $24(21.8)$ \\
\hline 2 & $24(21.8)$ \\
\hline$\geq 3$ & $62(56.4)$ \\
\hline \multicolumn{2}{|l|}{ Metastasis site } \\
\hline Bone & $80(72.7)$ \\
\hline Viscera & $76(69.1)$ \\
\hline Liver & $51(46.4)$ \\
\hline Lung & $48(43.6)$ \\
\hline \multicolumn{2}{|l|}{ Previous endocrine therapy } \\
\hline Tamoxifen & $77(70.0)$ \\
\hline Letrozole or anastrozole & $86(78.2)$ \\
\hline Exemestane & $58(52.7)$ \\
\hline Fulvestrant & $37(33.6)$ \\
\hline \multicolumn{2}{|c|}{ Endocrine drugs during last therapy } \\
\hline Tamoxifen & $15(13.6)$ \\
\hline Letrozole or anastrozole & $32(29.1)$ \\
\hline Exemestane & $28(25.5)$ \\
\hline Fulvestrant & $29(26.4)$ \\
\hline \multicolumn{2}{|l|}{ Combined endocrine drugs } \\
\hline Anti-estrogens & $19(17.3)$ \\
\hline Letrozole or anastrozole & $25(22.7)$ \\
\hline Exemestane & $45(40.9)$ \\
\hline Fulvestrant & $20(18.2)$ \\
\hline Medroxyprogesterone & $1(0.9)$ \\
\hline
\end{tabular}

Table 1 (continued)
Table 1 (continued)

\begin{tabular}{lc}
\hline Characteristic & Number of cases $(\%)$ \\
\hline Number of lines of salvage endocrine therapy & \\
Median [range] & $3[1-8]$ \\
1 & $11(10.0)$ \\
2 & $36(32.7)$ \\
$\geq 3$ & $63(57.3)$ \\
Number of lines of salvage chemotherapy & \\
Median [range] & $3[0-11]$ \\
0 & $14(12.7)$ \\
1 & $20(18.2)$ \\
2 & $17(15.5)$ \\
$\geq 3$ & $59(53.6)$ \\
\hline
\end{tabular}

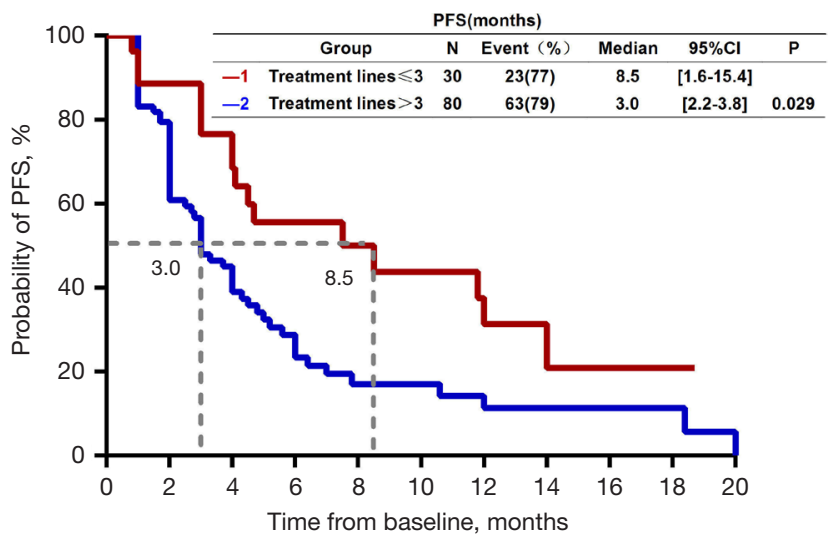

Figure 1 Progression-free survival curves for patients on different numbers of treatment lines.

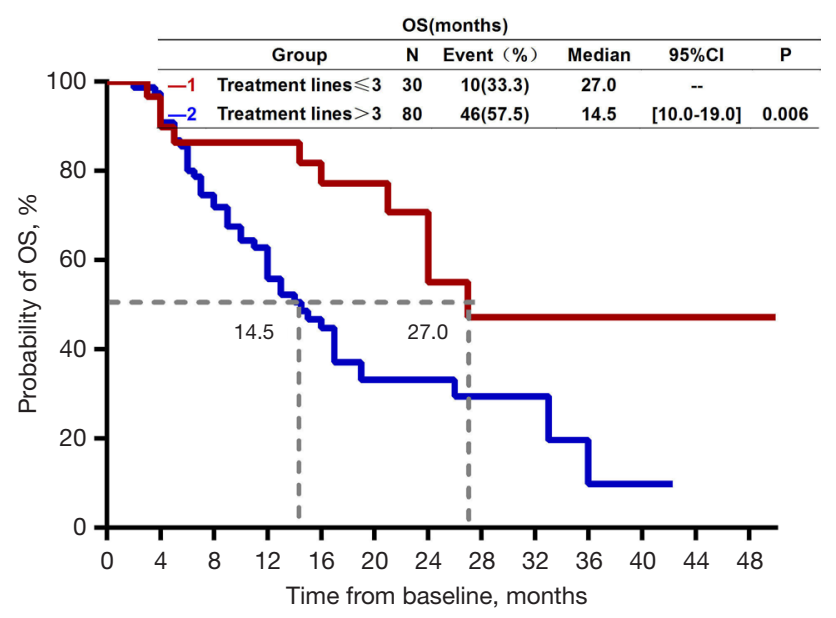

Figure 2 Overall survival curves for patients on graded number of treatment lines. 


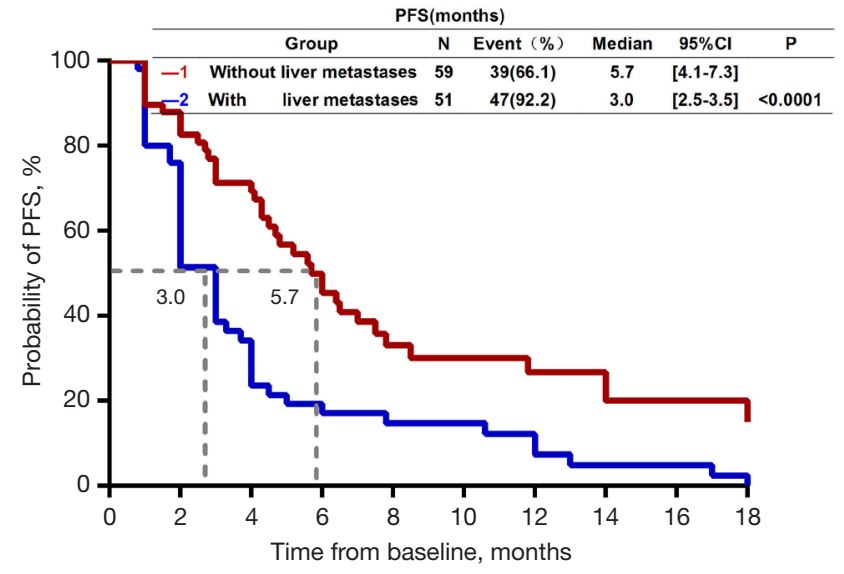

Figure 3 Progression-free survival curves for patients with or without liver metastases.

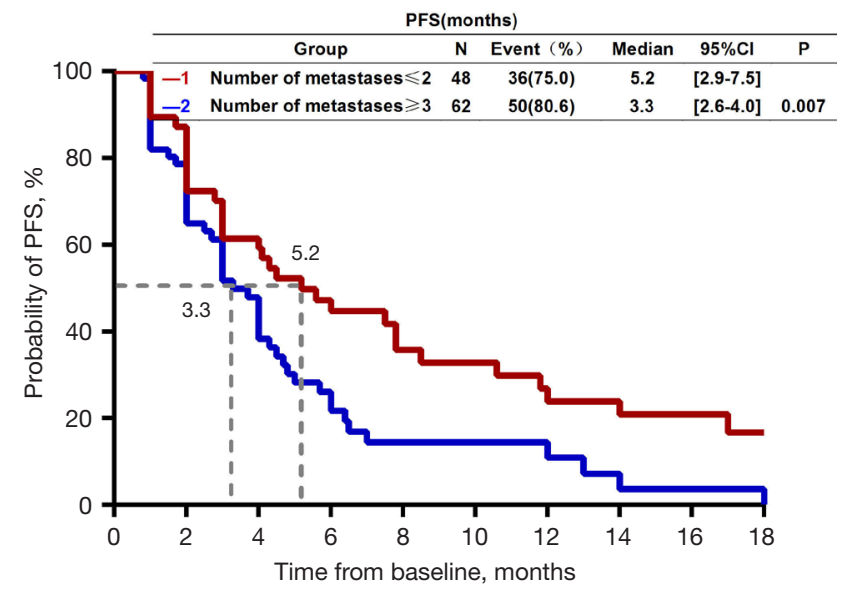

Figure 4 Progression-free survival curves for patients with different numbers of metastases.

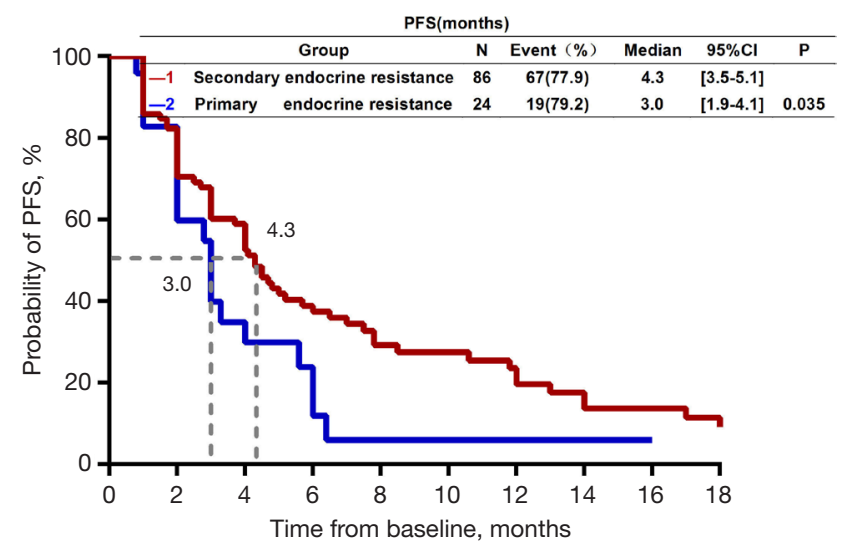

Figure 5 Progression-free survival curves for patients with primary and secondary endocrine resistance.

\section{Efficacy}

Until November 2017, the median follow-up period was 12 months (range: $1-56.3$ months). Treatment was terminated in 86 patients $(78.2 \%)$ due to disease progression; medication was discontinued in 12 patients $(10.9 \%)$ due to intolerance of adverse reactions to everolimus and in 7 patients $(6.4 \%)$ due to other reasons; and treatment was continued in 5 patients (4.5\%). Fiftysix patients $(50.9 \%)$ died, 13 patients $(11.8 \%)$ were lost to follow-up, and $41(37.3 \%)$ patients survived. Among the 110 patients, there were 7 cases of partial response, and 28 cases of stable disease exceeding 6 months, no complete response case. The ORR was $6.4 \%$, the CBR was $31.8 \%$, the median progression-free survival (mPFS) was 4.0 months (95\% CI: 2.9-5.1 months), and the median OS was 17 months (95\% CI: 12.1-21.9 months). The mPFS of patients who received $\leq 2$ treatment lines was 11.8 months (95\% CI: $4.3-19.3$ months), and that of patients who received $\leq 3$ treatment lines was 8.5 months (95\% CI: 1.6-15.4 months). Compared with patients who received $>3$ treatment lines, the PFS and OS of patients who received $\leq 3$ treatment lines were significantly longer (Figures 1,2). Among the 40 patients $(36.4 \%$ ) with resistance to non-steroidal aromatase inhibitors who received everolimus combined with exemestane, the mPFS of 11 patients $(27.5 \%)$ who received $\leq 3$ treatment lines was 8.5 months (95\% CI: $1.0-16.4$ months). Univariate and multivariate analyses showed that patients without hepatic metastases and secondary endocrine resistance and number of metastatic sites $<3$ were more likely to benefit from everolimus combined with endocrine therapy (Figures 3-5, Tables 2,3). Following the principle of avoiding the use of previously ineffective endocrine drugs, the combinations of everolimus with different endocrine drugs did not show significant differences (Figure 6).

\section{Adverse reactions}

The adverse events of the 110 patients are listed in Table 4 . No grade 4 adverse reactions were observed, and no patients died of treatment-related adverse reactions. Administration of everolimus was discontinued in 12 patients (10.9\%) due to adverse reactions, including 6 cases of non-infectious pneumonia, 1 case of stomatitis (grade 3 adverse reactions), 2 cases of non-inductive pneumonia and stomatitis, 1 case of erythra (grade 3 adverse reactions), 1 case of hemorrhagic cystitis, 1 case of proteinuria. The incidence of non- 
Table 2 Univariate analysis of factors affecting PFS

\begin{tabular}{|c|c|c|c|c|}
\hline Factor & $\begin{array}{c}\text { PFS } \\
\text { (month) }\end{array}$ & $\mathrm{HR}$ & $95 \% \mathrm{Cl}$ & $P$ \\
\hline Age & & 0.92 & $0.54-1.6$ & 0.767 \\
\hline$<60, n=88$ & 4.0 & & & \\
\hline$\geq 60, n=22$ & 4.1 & & & \\
\hline Body mass index & & 0.98 & $0.64-1.5$ & 0.911 \\
\hline$<$ Mean, $\mathrm{n}=60$ & 3.0 & & & \\
\hline$\geq$ Mean, $n=47$ & 4.5 & & & \\
\hline Combined endocrine drugs & & 1.0 & $0.81-1.25$ & 0.367 \\
\hline Anti-estrogens, $n=19$ & 4.7 & & & \\
\hline $\begin{array}{l}\text { Letrozole or anastrozole, } \\
n=25\end{array}$ & 4.3 & & & \\
\hline Exemestane, $n=45$ & 4.0 & & & \\
\hline Fulvestrant, $\mathrm{n}=20$ & 3.0 & & & \\
\hline Medroxyprogesterone, $\mathrm{n}=1$ & 1.7 & & & \\
\hline Liver metastases & & 2.1 & $1.36-3.24$ & $<0.0001$ \\
\hline No, $n=59$ & 5.7 & & & \\
\hline Yes, $n=51$ & 3.0 & & & \\
\hline Lung metastases & & 1.25 & $0.81-1.92$ & 0.297 \\
\hline No, $n=62$ & 4.3 & & & \\
\hline Yes, $n=48$ & 4.0 & & & \\
\hline Bone metastases & & 1.81 & $1.09-2.99$ & 0.015 \\
\hline No, $n=30$ & 6.0 & & & \\
\hline Yes, $n=80$ & 3.0 & & & \\
\hline Number of metastasis sites & & 1.79 & $1.15-2.80$ & 0.007 \\
\hline$\leq 2, n=48$ & 5.2 & & & \\
\hline$\geq 3, n=62$ & 3.3 & & & \\
\hline $\begin{array}{l}\text { Number of lines of salvage } \\
\text { chemotherapy }\end{array}$ & & 1.74 & $1.13-2.69$ & 0.008 \\
\hline$\leq 2, n=51$ & 5.2 & & & \\
\hline$\geq 3, n=59$ & 3.0 & & & \\
\hline Menstrual status & & 1.04 & $0.67-1.61$ & 0.869 \\
\hline Premenopausal, $n=40$ & 4.0 & & & \\
\hline Postmenopausal, $n=70$ & 4.0 & & & \\
\hline Endocrine resistance & & 0.61 & $0.36-0.81$ & 0.035 \\
\hline Primary resistance, $n=24$ & 3.0 & & & \\
\hline Secondary resistance, $\mathrm{n}=86$ & 4.3 & & & \\
\hline
\end{tabular}

Table 2 (continued)
Table 2 (continued)

\begin{tabular}{lcccc}
\hline Factor & $\begin{array}{c}\text { PFS } \\
\text { (month) }\end{array}$ & HR & $95 \% \mathrm{Cl}$ & $\mathrm{P}$ \\
\hline Disease-free survival & & 0.85 & $0.55-1.31$ & 0.438 \\
$\leq 24$ months, $\mathrm{n}=43$ & 3.0 & & & \\
$>24$ months, $\mathrm{n}=67$ & 4.0 & & & \\
Grade of treatment line & & 1.67 & $1.03-2.7$ & 0.029 \\
$\leq 3, \mathrm{n}=30$ & 8.5 & & & \\
$>3, \mathrm{n}=80$ & 3.0 & & & \\
Grade of endocrine line & & 1.43 & $0.92-2.22$ & 0.095 \\
$\leq 2, \mathrm{n}=47$ & 4.5 & & & \\
$\geq 3, \mathrm{n}=63$ & 3.3 & & & \\
\hline
\end{tabular}

PFS, progression-free survival; $\mathrm{HR}$, hazard ratio; $\mathrm{Cl}$, confidence interval.

Table 3 Multivariate analysis of factors affecting PFS

\begin{tabular}{|c|c|c|c|c|}
\hline Factor & $\begin{array}{c}\text { PFS } \\
\text { (month) }\end{array}$ & $\mathrm{HR}$ & $95 \% \mathrm{Cl}$ & $\mathrm{P}$ \\
\hline Liver metastases & & 2.04 & $1.31-3.18$ & 0.002 \\
\hline No, $n=59$ & 5.7 & & & \\
\hline Yes, $n=51$ & 3.0 & & & \\
\hline Bone metastases & & 1.48 & $0.86-2.54$ & 0.133 \\
\hline No, $n=30$ & 6.0 & & & \\
\hline Yes, $n=80$ & 3.0 & & & \\
\hline Number of metastasis sites & & 1.72 & $1.09-2.72$ & 0.021 \\
\hline$\leq 2, n=48$ & 5.2 & & & \\
\hline$\geq 3, n=62$ & 3.3 & & & \\
\hline $\begin{array}{l}\text { Number of lines of salvage } \\
\text { chemotherapy }\end{array}$ & & 1.11 & $0.59-2.11$ & 0.48 \\
\hline$\leq 2, n=51$ & 5.2 & & & \\
\hline$\geq 3, n=59$ & 3.0 & & & \\
\hline Endocrine resistance & & 0.52 & $0.30-0.88$ & 0.015 \\
\hline Primary resistance, $n=24$ & 3.0 & & & \\
\hline Secondary resistance, $\mathrm{n}=86$ & 4.3 & & & \\
\hline Grade of treatment line & & 1.02 & $0.52-2.01$ & 0.765 \\
\hline$\leq 3, n=30$ & 8.5 & & & \\
\hline$>3, n=80$ & 3.0 & & & \\
\hline
\end{tabular}

PFS, progression-free survival; $\mathrm{HR}$, hazard ratio; $\mathrm{Cl}$, confidence interval. 


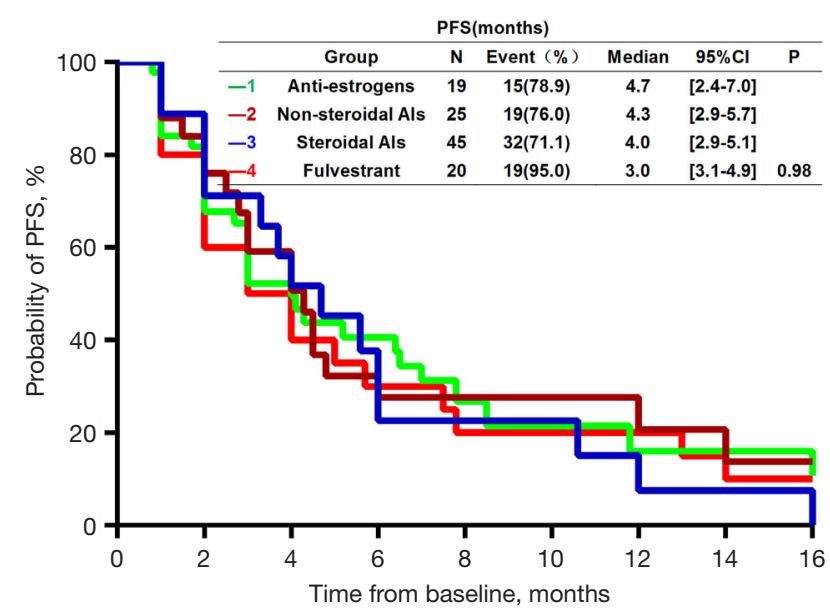

Figure 6 Progression-free survival curves for patients on different endocrine drugs.

Table 4 Adverse reactions

\begin{tabular}{lcc}
\hline Adverse reactions & All grades $(\mathrm{n}, \%) \geq$ Grade $3(\mathrm{n}, \%)$ \\
\hline Non-hematological adverse reactions & \\
Stomatitis & $24(21.8)$ & $6(5.5)$ \\
Non-infectious pneumonia & $22(20.0)$ & $2(1.8)$ \\
Fatigue & $20(18.2)$ & $0(0)$ \\
Erythra & $10(9.1)$ & $2(1.8)$ \\
Body weight loss & $7(6.4)$ & $0(0)$ \\
Hematological adverse reactions & & \\
Anemia & $25(22.7)$ & $0(0)$ \\
Leukopenia & $15(13.6)$ & $1(0.9)$ \\
Thrombocyopenia & $14(12.7)$ & $1(0.9)$ \\
Elevated blood sugar & $26(23.6)$ & $1(0.9)$ \\
$\begin{array}{l}\text { Elevated alanine } \\
\text { aminotransferase }\end{array}$ & $31(28.2)$ & $0(0)$ \\
Elevated aspartate & & $0(0)$ \\
aminotransferase & $40(36.4)$ & \\
\hline
\end{tabular}

hematologic and hematological adverse reactions was lower or similar to that reported in previous studies.

\section{Discussion}

Resistance to endocrine therapy remains a big challenge in clinical practice. CDK4/6 inhibitors have significantly improved overall survival for patients with HR-positive and
HER2-negative advanced breast cancer, while this study is the clinical application of everolimus before approval of CDK4/6 inhibitors in China. There have been clinical data indicated that everolimus maybe a potential treatment after CDK4/6 inhibitors resistance (22). One of the mechanisms of endocrine resistance is the activation of the growth factor receptor $\mathrm{PI} 3 \mathrm{k} / \mathrm{AKT} / \mathrm{mTOR}$ signaling pathway. The BOLERO-2 study (23) compared the efficacy of a combination of the mTOR inhibitor everolimus with the endocrine therapy exemestane and exemestane alone in advanced breast cancer patients with resistance to endocrine therapy. The results revealed that the combination therapy could significantly prolong PFS. The BOLERO-2 study confirmed that everolimus combined with exemestane could effectively improve PFS in patients with advanced breast cancer who did not respond well to non-steroidal aromatase inhibitors. Everolimus combined with endocrine drugs might be considered a cost-effective option compared with other endocrine therapies for HR-positive and HER2-negative metastatic breast cancer as second-line therapy (24). However, in the BOLERO-2 study, patients showed a higher rate of treatment interruption and an increased incidence of adverse reactions. The median dose of everolimus was $8.6 \mathrm{mg} / \mathrm{day}$, and the dose ranged from $0.9-1.1$ and $0.5-0.7$ in $19 \%$ and $17 \%$ of patients, respectively. Moreover, in $62 \%$ of patients the dose was reduced or interrupted (16). The subgroup analysis showed that the overall incidence of adverse reactions such as stomatitis, pneumonia, and erythra in Asians (excluding Chinese) was higher than in non-Asians, with a similar incidence of grade 3 or higher adverse reactions (23). In the BALLET study, medication was interrupted in $56.2 \%$ of patients who received everolimus $10 \mathrm{mg} /$ day; the dose was changed in $59.6 \%$ of patients, which was similar to the results reported in BOLERO-2 (17). Xu et al. showed that in Chinese patients, the incidence of adverse reactions in the everolimus $10 \mathrm{mg}$ group was almost twice that of the $5 \mathrm{mg}$ group, and the absolute value of efficiency of the $5 \mathrm{mg}$ group was higher than that of the $10 \mathrm{mg}$ group (25). In the present study, everolimus treatment was discontinued in 12 patients due to adverse reactions, while in only $3(2.7 \%)$ patients, it was discontinued due to grade 3 adverse reactions.

Ciccarese $e t$ al. (18) retrospectively analyzed the efficacy and safety of everolimus administered at different initial doses $(10 \mathrm{mg} /$ day, $5 \mathrm{mg} /$ day) in 163 patients. These patients were divided into Groups A, B, and C according to different doses of everolimus. Group A, which included 84 patients (51.6\%), was continuously given $10 \mathrm{mg} /$ day or resumed a dose of $10 \mathrm{mg} /$ day if there were temporary interruptions; 
Group B, which included 54 patients (33.1\%), was given an initial dose of $5 \mathrm{mg} /$ day or an initial dose of $10 \mathrm{mg} /$ day, which was subsequently reduced to $5 \mathrm{mg} /$ day; and Group C consisted of 25 patients (15.3\%) and was given 10 or $5 \mathrm{mg} /$ day. The results revealed drug effectiveness of $29.8 \%$ and $27.8 \%$, and PFSs of 9 and 10 months in Groups A and $\mathrm{B}$, respectively, thus suggesting no significant difference between the $10 \mathrm{mg} /$ day group and $5 \mathrm{mg} /$ day group. In the present study, we retrospectively analyzed the realworld clinical data of advanced breast cancer patients with hormone receptor-positive, who were given everolimus ( $5 \mathrm{mg} /$ day) combined with endocrine drugs. We found that in patients who received $\leq 2$ and $\leq 3$ treatment lines, had mPFSs of 11.8 and 8.5 months, respectively, which was comparable to the retrospective analysis results reported by Ciccarese et al. (18). Meanwhile, in the BOLERO-2 study, the mPFS of everolimus combined with exemestane was 11 months, which was similar to that of patients who received $\leq 2$ treatment lines in the present study. The reason for the similar drug effectiveness may be due to the good tolerability of everolimus at a dose of $5 \mathrm{mg} /$ day, which leads to better treatment compliance and similar drug effectiveness compared with a dose of $10 \mathrm{mg} /$ day. Another study (26) showed that a low body mass index (BMI) might indicate better effectiveness of everolimus combined with exemestane, which suggests that an everolimus dose of $5 \mathrm{mg}$ /day may be feasible in the Chinese population as their median BMI is lower than that of European and American patients.

This study has the following limitations: it is a singlecenter retrospective study with a relatively small sample size, which may lead to certain biases.

\section{Conclusions}

Everolimus ( $5 \mathrm{mg} /$ day) combined with endocrine therapy is effective and relatively safe for patients with hormone receptor-positive metastatic breast cancer. The absence of liver metastases, secondary endocrine resistance, and a number of metastasis sites $<3$ were among many factors influencing the benefit of everolimus combined with endocrine therapy. Additional studies with larger sample sizes are required to confirm these findings.

\section{Acknowledgments}

We would like to thank all patients and their families for participating in the study. We would also like to thank the staff at the Fifth Medical Center of Chinese PLA General
Hospital for support of the study.

Funding: This study was supported by Beijing Municipal Natural Science Funding (General Program) (Grant No. 7192198).

\section{Footnote}

Reporting Checklist: The authors have completed the STROBE reporting checklist. Available at https://dx.doi. org/10.21037/atm-21-4273

Data Sharing Statement: Available at https://dx.doi. org/10.21037/atm-21-4273

Conflicts of Interest: All authors have completed the ICMJE uniform disclosure form (available at https://dx.doi. org/10.21037/atm-21-4273). The authors have no conflicts of interest to declare.

Ethical Statement: The authors are accountable for all aspects of the work in ensuring that questions related to the accuracy or integrity of any part of the work are appropriately investigated and resolved. All procedures performed in this study involving human participants were in accordance with the Declaration of Helsinki (as revised in 2013). The study was approved by ethics board of The Fifth Medical Center of the Chinese People's Liberation Army General Hospital (formerly named the 307 Hospital of Chinese People's Liberation Army) (No. 2010-06-64) and informed consent was taken from all the patients.

Open Access Statement: This is an Open Access article distributed in accordance with the Creative Commons Attribution-NonCommercial-NoDerivs 4.0 International License (CC BY-NC-ND 4.0), which permits the noncommercial replication and distribution of the article with the strict proviso that no changes or edits are made and the original work is properly cited (including links to both the formal publication through the relevant DOI and the license). See: https://creativecommons.org/licenses/by-nc-nd/4.0/.

\section{References}

1. Chen $\mathrm{W}$, Zheng R, Baade PD, et al. Cancer statistics in China, 2015. CA Cancer J Clin 2016;66:115-32.

2. Cleator SJ, Ahamed E, Coombes RC, et al. A 2009 update on the treatment of patients with hormone receptor-positive breast cancer. Clin Breast Cancer 
2009;9 Suppl 1:S6-S17.

3. Xu F, Jiang Z. CSCO BC guideline: updates for hormone receptor-positive breast cancer in 2020. Transl Breast Cancer Res 2020;1:3.

4. Untch M, Augustin D, Ettl J, et al. ABC3 Consensus Commented from the Perspective of the German Guidelines: Third International Consensus Conference for Advanced Breast Cancer (ABC3), Lisbon, 07.11.2015. Geburtshilfe Frauenheilkd 2016;76:156-63.

5. Schiff R, Massarweh SA, Shou J, et al. Cross-talk between estrogen receptor and growth factor pathways as a molecular target for overcoming endocrine resistance. Clin Cancer Res 2004;10:331S-6S.

6. Miller TW, Balko JM, Arteaga CL. Phosphatidylinositol 3-kinase and antiestrogen resistance in breast cancer. J Clin Oncol 2011;29:4452-61.

7. Boulay A, Rudloff J, Ye J, et al. Dual inhibition of mTOR and estrogen receptor signaling in vitro induces cell death in models of breast cancer. Clin Cancer Res 2005;11:5319-28.

8. Beeram M, Tan QT, Tekmal RR, et al. Akt-induced endocrine therapy resistance is reversed by inhibition of mTOR signaling. Ann Oncol 2007;18:1323-8.

9. Kornblum NS, Manola J, Klein P, et al. Abstract s1-02: Precog 0102: A randomized, double-blind, phase ii trial of fulvestrant plus everolimus or placebo in post-menopausal women with hormone receptor (hr)-positive, her2-negative metastatic breast cancer (mbc) resistant to aromatase inhibitor (ai) therapy. Cancer Res 2017;77:S1-02.

10. Bachelot T, Bourgier C, Cropet C, et al. Randomized phase II trial of everolimus in combination with tamoxifen in patients with hormone receptor-positive, human epidermal growth factor receptor 2-negative metastatic breast cancer with prior exposure to aromatase inhibitors: a GINECO study. J Clin Oncol 2012;30:2718-24.

11. Yardley DA, Noguchi S, Pritchard KI, et al. Everolimus plus exemestane in postmenopausal patients with $\mathrm{HR}(+)$ breast cancer: BOLERO-2 final progression-free survival analysis. Adv Ther 2013;30:870-84.

12. Lousberg L, Jerusalem G. Safety, Efficacy, and Patient Acceptability of Everolimus in the Treatment of Breast Cancer. Breast Cancer (Auckl) 2016;10:239-52.

13. Awada A, Cardoso F, Fontaine C, et al. The oral mTOR inhibitor RAD001 (everolimus) in combination with letrozole in patients with advanced breast cancer: results of a phase I study with pharmacokinetics. Eur J Cancer 2008;44:84-91.

14. Tabernero J, Rojo F, Calvo E, et al. Dose- and schedule- dependent inhibition of the mammalian target of rapamycin pathway with everolimus: a phase I tumor pharmacodynamic study in patients with advanced solid tumors. J Clin Oncol 2008;26:1603-10.

15. Ellard SL, Clemons M, Gelmon KA, et al. Randomized phase II study comparing two schedules of everolimus in patients with recurrent/metastatic breast cancer: NCIC Clinical Trials Group IND.163. J Clin Oncol 2009;27:4536-41.

16. Rugo HS, Pritchard KI, Gnant M, et al. Incidence and time course of everolimus-related adverse events in postmenopausal women with hormone receptor-positive advanced breast cancer: insights from BOLERO-2. Ann Oncol 2014;25:808-15.

17. Jerusalem G, Mariani G, Ciruelos EM, et al. Safety of everolimus plus exemestane in patients with hormonereceptor-positive, HER2-negative locally advanced or metastatic breast cancer progressing on prior non-steroidal aromatase inhibitors: primary results of a phase IIIb, open-label, single-arm, expanded-access multicenter trial (BALLET). Ann Oncol 2016;27:1719-25.

18. Ciccarese M, Fabi A, Moscetti L, et al. Dose intensity and efficacy of the combination of everolimus and exemestane (EVE/EXE) in a real-world population of hormone receptor-positive (ER+/PgR+), HER2-negative advanced breast cancer $(\mathrm{ABC})$ patients: a multicenter Italian experience. Breast Cancer Res Treat 2017;163:587-94.

19. Freedman RA, Tolaney SM. Efficacy and safety in older patient subsets in studies of endocrine monotherapy versus combination therapy in patients with HR+/HER2advanced breast cancer: a review. Breast Cancer Res Treat 2018;167:607-14.

20. Gong C, Zhao Y, Wang B, et al. Efficacy and safety of everolimus in Chinese metastatic HR positive, HER2 negative breast cancer patients: a real-world retrospective study. Oncotarget 2017;8:59810-22.

21. Eisenhauer EA, Therasse P, Bogaerts J, et al. New response evaluation criteria in solid tumours: revised RECIST guideline (version 1.1). Eur J Cancer 2009;45:228-47.

22. Xi J, Ma CX. Sequencing Endocrine Therapy for Metastatic Breast Cancer: What Do We Do After Disease Progression on a CDK4/6 Inhibitor? Curr Oncol Rep 2020;22:57.

23. Noguchi S, Masuda N, Iwata H, et al. Efficacy of everolimus with exemestane versus exemestane alone in Asian patients with HER2-negative, hormone-receptorpositive breast cancer in BOLERO-2. Breast Cancer 2014;21:703-14. 


\section{Page 10 of 10}

24. Xie J, Hao Y, Zhou ZY, et al. Economic Evaluations of Everolimus Versus Other Hormonal Therapies in the Treatment of HR+/HER2- Advanced Breast Cancer From a US Payer Perspective. Clin Breast Cancer 2015;15:e263-76.

25. Xu B, Wu Y, Shen L, et al. Two-dose-level confirmatory study of the pharmacokinetics and tolerability of everolimus in Chinese patients with advanced solid tumors.
Zhang et al. Low dose everolimus in the treatment for breast cancer

J Hematol Oncol 2011;4:3.

26. Pizzuti L, Marchetti P, Natoli C, et al. Fasting glucose and body mass index as predictors of activity in breast cancer patients treated with everolimus-exemestane: The EverExt study. Sci Rep 2017;7:10597.

(English Language Editor: B. Meiser)
Cite this article as: Zhang HQ, Zhou JM, Zhang SH, Bian L, Xiao JY, Hao XP, Jiang ZF, Wang T. Efficacy and safety of lowdose everolimus combined with endocrine drugs for patients with hormone receptor-positive, human epidermal growth factor receptor 2-negative metastatic breast cancer. Ann Transl Med 2021;9(19):1493. doi: 10.21037/atm-21-4273 